\title{
Strategies to Boost the Moral Construction of Chinese Citizens in the Process of Basic Modernization*
}

\author{
Xiangyong Dong \\ Faculty of Humanities \\ Huaiyin Institute of Technology \\ Huaian, China 223003
}

\begin{abstract}
The basic realization of modernization on the basis of building a moderately well-off society in an all-round way is a significant stage of the modernization development of Chinese society. In the stage with distinctive features of the times, extremely targeted planning on the corresponding strategy level must be made to boost the moral construction of citizens. Related efforts must base on the new development of the new times and cannot contradict with the target that boosts the moral construction of citizens. Meanwhile, it must pay equal attention to strengthening the guidance and detailing the operation and select good resources and optimize means simultaneously as well as make cultural edification keep abreast of platform improvement. A constantly perfected strategy system must be formed in the development when multiple measures are taken "concurrently".
\end{abstract}

Keywords-basic modernization; the moral construction of citizens; boost; strategies

\section{INTRODUCTION}

China's social change since the reform and opening up has not only brought the realistic progress but also contained the confidence and expectation of Chinese people for a wider and deeper development. Meanwhile, for China and Chinese society, the reality of progress has constituted the start of brand-new development, but the confidence and expectation on the brand-new development produced on the basis of reality becomes an indispensable intellectual impetus, even determining the direction and pace of future development. Therefore, there is no need to repeat its importance. Specifically speaking, the most key part of the confidence and expectation of Chinese people at present and in ten or twenty years is the basic modernization. It's worth pointing out that the basic modernization should not be simply regarded as the continuation of the history of struggle of Chinese nation in modern times. On the contrary, the continuation of history can only be one of the pursuits of the modernization struggle under the new historical conditions. However, the more typical part of its feature in time dimension is that it is gradually established in the construction, reform and development of Chinese society and the "modernization"

*Fund program: General project of the philosophy and society study of universities in Jiangsu Province, "On the Strategies to Make the Traditional Moral Composition Idea Facing the Pursuit of Self-actualization of Students Involve in the Moral Education Practice of Universities" (2016SJB710107), and subsidized by the overseas study program for excellent young teachers and principals in universities of Jiangsu province. form full of the breath of the new era. Except for the selfevident deep level, the basic modernization should be of course all-around on content. However, anyway, it cannot be denied that the modernization of people must be contained and the core of it. Closely related to the multi-dimensional pursuit of people, the modernization of people also must be profound and comprehensive, especially as the only existence with not pure natural meaning. People cannot neglect the modernization on the economic level produced because of survival and life. But compared with the modernization of people's spiritual world, the previous is evidently the basic level. Therefore, bluntly speaking, the ultimate meaning of the modernization of people is the spiritual element, namely the modernization of high-level content constituted by the meaning of people. On the basis of the profound understanding of modernization, in the effort of the basic modernization, we must take the moral quality of citizens as an important soft power, the improvement of the moral quality of citizens as an important hard target. All of them depend on the deep boosting of the moral construction of citizens. Particularly, we must customize strategies that conform to the basic modernization to boost the moral construction of citizens.

\section{TO STRIVE TO IMPROVE THE SEAMLESS MORAL EDUCATION SYSTEM}

In boosting the moral construction of citizens in the process of basic modernization, we must stick to the direction and cling to the target as well as proactively innovate in the working ideas on the basis of our development. Meanwhile, measures must be innovated in thinking the specific boosting methods. In the various concrete efforts, ceaselessly strengthening and perfecting the seamless moral education system is the priority among priorities. After all, boosting the moral education of citizens will inevitably face the problem that when and where to conduct moral education for citizens. In addition, the systematic and solid characteristic of the moral education of citizens correspondingly requires us to adjust measures to time and place and realize seamless connection in different time and space conditions.

In the first place, family is the basic unit of society and family ethic is the basic part of social morality. Therefore, we must attach importance to moral education in family and unceasingly enrich methods and ways of the moral education in family to improve the efficiency of it. In the process of 
basic modernization, according to the demand of the times, we should strive to promote the generation and development of family virtues in the new era in each family and let families truly become the primary base for social individuals to enhance moral consciousness. In the second place, except for serving as an important place for people to learn knowledge, school is indispensable in developing morality and personality. Therefore, it requires schools to carry out moral education via extensive thinking and multiple channels and assist students to develop morality. Particularly, nowadays, the scale and quality of education in China has achieved a certain level. Further intensifying the function of moral education of schools at all levels and creating schools into the place of moral education that integrates multiple dimensions and cohesion will concern not only the improvement of education quality but also what kind of successors it will cultivate. In the third place, workplace is the place for people to work and improve. In terms of China at the present stage, it is an unquestioned fact that non-public enterprises have increased. Detailed, careful and practical design must be made to carry out moral education more explicitly. In the process of basic modernization, regardless of the nature and scale of workplaces, they must shoulder corresponding responsibilities of moral education in society and widen the channel of improving the moral realm of employees and ceaselessly enrich their moral quality.

The moral education of citizens depends on the continuous and seamless moral education system in the society. From the perspective of concrete composition, family, school and workplace should be covered. Besides, other aspects such as community and neighborhood committee are the force of powerful boosting. They have different functional orientation, but they are important parts of the moral education system in the society. Because of their distinctive feature of social organization, its efficiency in boosting the moral construction of citizens under the background of the new times will be beyond our imagination. What is worth mentioning is that they connect families and schools downwards and connect organizations and institutions at all levels upwards, belonging to the typical "media" form. They have unique advantages in the aspect of integrating resources of the moral education in the society. They play the special role of connection and bonding in the specific implementation of the moral education of citizens. Furthermore, since the system must be rigorous and neat, in the process of the moral construction of citizens, we must optimize the connection of elements in the moral education of the society, break the limitation of time and space in moral education and correspondingly make it allaround, creating a stagger and solid education of moral education for the audiences. Therefore, in the process of basic modernization, we must intensify the construction of the moral education system in society that contains schools, families, communities and neighborhood committees. When strengthening the functions of specific elements, we should enhance the connection and interaction of elements in the system, build the lubricating mechanism of elements with features of the new era as well as optimize it via keeping pace with the times, so that we will enhance the overall quality and operational efficiency of the moral education system of the society on the basis of ensuring the seamless connection of specific elements.

In general, in the process of basic modernization, boosting the moral construction of citizens depends on the seamless moral education system in society. On one hand, we must certainly put effort into strengthening the function of families, schools and communities and optimize the function of a single element. On the other hand, more importantly, related mechanism and rules must be improved to eradicate the gap even barrier between elements in the system. At the same time, we should endeavor to promote the formation of the efficient interaction between elements and build a smooth and integrated moral education system in the society.

\section{To SElECt Elaborate AND VARIOUS MORAL RESOURCES}

In the effort of enriching the moral quality of citizens, which recourses of moral education can be adopted will depend on the specific social and historical conditions. It is determined by the social history of moral resources and required by the specific practical development. In the process of basic modernization, striving to boost the moral education of citizens must base on the practical development and corresponding target system. After discriminating and choosing, we must reasonably make use of various excellent moral resources to serve and boost the moral construction of citizens

Because the traditional moral resources of Chinese nation substantially belong to the traditional Chinese spirit, it "accumulates the deepest spiritual pursuit of the Chinese nation and represents the unique spiritual identity of the Chinese nation." [1] It has united the moral pursuit of the Chinese nation and its deep-level expansion and been the moral resources of the Chinese nation with distinctive features Therefore, under the premise of envisaging it is formed under the specific time-and-space background, scientifically excavating and striving to give play to the related content has a positive value on the social development at present. It requires us to conduct multi-dimensional and deep-level examination on the traditional national moral resources and choose excellent contents with a strong vitality. On the other hand, we must divest the historic limitations of some moral resources and correspondingly endow it with realistic vitality. What is more, necessary selection and transformation is required to extract the content that plays a role in boosting the moral construction of citizens. Methods and paths must be proactively optimized to furthest give play to the function of the traditional moral resources of the Chinese nation.

We can also pick over the good moral resources that do not belong to the Chinese nation. However, we should first realize the effect will not be good if we mechanically imitate the moral resources formed at abroad at different times, and it must go through the process of being endowed with "Chinese" characteristics. Therefore, we must conduct deeper-level discrimination and transformation on it to eliminate the time and space limitations of specific moral resources. In particular, in face of the moral resources of the West in modern times, we should even more carry out the work, because they belong to the moral category of 
bourgeoisie. If we do not discriminate and transform, it may influence the fundamental direction of the moral construction of citizens, except for creating new contradictions for social development. Therefore, on the basis of stage characteristics of the basic modernization in China, we should adhere to the principle of choosing the good and make use of it, deeply discriminate and transform the moral resources that do not belong to the Chinese nation via such specific means as deep excavation and discrimination and make it serve the boosting of the moral construction of citizens.

On one hand, as the combination of the moral pursuit and struggle of Chinese people, the moral resources formed in the process of the revolution, construction and reform of Chinese people in modern times have become a significant part of the excellent moral resources of the Chinese nation. On the other hand, it obviously has more modern colors, compared with the traditional moral resources of the Chinese nation. Particularly, the excellent moral resources that are formed under the brandnew condition of the reform and opening up are the accumulation of the achievements of moral construction in Chinese society. In the process of basic modernization, it is undoubted that these resources can directly serve the boosting of the moral construction of citizens. Most importantly, we must pay high attention to the demonstration effect of moral models and advanced persons in the new era, systematically and deeply present the method of giving full play to the demonstration effect and extend to the level of giving play to the role of other moral resources.

In truthful words, in boosting the moral construction of citizens in the process of basic modernization, we must strive to select good moral resources and meet the material requirements to the largest extent. Selecting good moral resources requires us to break the limitation of time and space. No matter it is Chinese or Western, from ancient times or modern times, if it is good, we will select and carry it forward. Of course, it means we should avoid the thought of mechanically imitating. On the contrary, the corresponding effort of discrimination, selection and transformation is indispensable, in order to ensure the moral resources that serve the moral construction of citizens in the new era.

\section{TO EXERT THE ADVANTAGES OF LOCAL CHARACTERISTIC CUlTURE Well}

Among the various methods of enhancing the moral quality of citizens, cultural edification is undoubtedly extremely crucial. On one hand, its path and effect of action are relatively direct because of its relationship with civic virtues. On the other hand, its function is more thorough than other elements on level because of its functional characteristics. Therefore, when boosting the moral construction of citizens in the process of basic modernization, we should make efforts to exert the function of cultural edification and must give full play to the role of superior culture especially in the actual implementation. Of course, the specific boosting of the moral construction of citizens in the new era will definitely carry out in specific time and space and it is correspondingly endowed with characteristics of time and space. According to the requirement of moral education in method and means, "specifically analyzing specific objects and specifically treating specific problems" [2] and local characteristic culture often has advantaged popularity, so the corresponding function will have more realistic pertinence, determining it is essential to highlight the function and value of local characteristic culture in the aspect of the function of cultural edification.

In exerting the advantages of local characteristic culture, we must stick to the purpose of boosting the moral construction of citizens and scientifically excavate the cultural resources of some place, such as the cultural custom, ethic habit and moral ideas with local characteristics formed in history, especially the characteristic cultural content produced after forty years since the reform and opening up. Then we should extract achievements that embody local spiritual civilization and the content that boosts the moral construction of citizens. However, it is necessary to emphasize that in the effort of boosting the moral construction of citizens in the new era, when excavating and extracting local characteristic cultures, we must stick to the principle of selecting excellent and advanced contents. The former bases on the nature of its content and requires the relevant cultural materials must be correct. The latter bases on its realistic characteristic and the relevant content must have modern value. Only by combining the two can we base on local characteristic and not disobey the nature of culture.

When exerting the advantages of local characteristic culture, we must optimize related mechanism of its function exertion. After all, corresponding to the idea update of people, the action mechanism of local characteristic culture is extremely complicated. Simple teaching or learning or mechanical teaching and learning are inopportune on the efficiency. Therefore, the boosting of the moral construction of citizens in the new era and the exertion of the advantages of local characteristic culture require us to take new measures in strengthening the interaction between culture and audiences. Of course, optimizing the function of local characteristic culture does not mean the advocacy of no teaching or no learning but emphasize innovating in method and path on the basis of the functional characteristics of culture and strive to influence others imperceptibly. In the process of basic modernization, we should systematically and consistently display the advantages of local characteristic culture that has more closeness in an imperceptible way to assist the improvement of the moral quality of citizens.

The exertion of the advantages of local characteristic culture is a process of continuously developing and enhancing local culture. In other words, in the effort of boosting the moral construction of citizens, better exerting the advantages of local characteristic culture will inevitably accumulate the corresponding moral resources, while promoting the excellent moral resources to rise to the level of local culture is the intrinsic requirement of the development of moral resources. The process of upgrading "excellence" to "advantage" has continuously enriched the connotation of local characteristic culture. At the meantime, ensuring the better conformance of it to the demand of the development of times will inevitably further expand the advantages of local culture. Only by making the best of local characteristic culture in boosting the moral construction of citizens and extracting excellent moral 
resources from the achievement of the moral construction of citizens then enriching local culture can we ensure its advantages and ceaselessly exert it.

To sum up, in the process of basic modernization, the concrete effort of boosting the moral construction of citizens must base on the corresponding characteristic of time and space and give full play to the advantages of local characteristic culture. First, we must extract excellent resources via excavation and condensation. Second, we must improve related mechanism and enhance its function and efficiency. Last, we need to have new thoughts and methods to accumulate and improve the excellent moral resources and unceasingly enrich local culture. At the same time, we can constantly intensify the power of the latter in boosting the moral construction of citizens.

\section{TO PROPERLY DEPEND ON THE PLATFORM OF PEOPLE- BASED ACTIVITY}

People-based activities are important platform of boosting the moral construction of citizens. However, closely linked to the ceaseless social development, people's life style has also presented brand-new characteristics. Specifically speaking, in terms of people-based activity, with the gradual disappearance of living style that people live in separate courtyard, the neighboring families in the original sense and its relationship increasingly become a memory. The people-based activity that bases on the living style and relationship inevitably faces the demand of "getting rid of the stale", and the continuous "bringing forth the fresh" of the people-based activity is gradually popular among people, which is the reflection of meeting the demand. Especially in the new era when the society develops rapidly, people's life has been enriched and diversified, which more or less is embodied via people-based activities. On the other hand, the influence of people-based activities on participants has become universal and profound. According to the characteristics and functions of people-based activity, in the process of basic modernization, the effort of boosting the moral construction of citizens has inevitably contained the proper dependence on the platform of peoplebased activity.

Some people-based activities have the direct purpose of building our body and also have the function of cultivating our moral character, such as morning exercise of doing Tai Chi and sword dance. The most representative is the square dancing in vogue. It is worthy of considering how to improve the spiritual realm of participants when building their body. Sticking to the target for the moral construction of citizens in the new era, we must expand the function of these peoplebased activities in cultivating their mind and integrate the moral contents of the era in costumes and prop, background music and movements as well as actually bring the moral education of citizens in it, in order to constantly enhance their moral taste. The activities can be created into the daily platform to boost the moral construction of citizens. We can better give play to their role in boosting the moral construction of citizens via efficient organization and scientific management.

Some people-based activities have taken leisure and entertainment as the direct purpose and have the function of cultivating our taste, such as collective movie, collective performance and collective chess game. People gain spiritual relaxation and pleasure through group leisure. There is no necessary to excessively emphasize its healthy and positive meaning. Its legal compliance of specific form is reasonable, so it constitutes an important platform for the moral construction of citizens. Under the target of boosting the moral construction of citizens, the proper exertion of the function of people-based activities must combine with the process of basic modernization to intensify their function in cultivating our taste. Appropriate methods and ways are required and relevant targets, contents and forms must be improved energetically to make people accept moral education and improve their moral quality when they gain spiritual pleasure.

Some people-based activities take relatively special groups as the subject, such as the activity in children's palace, in the activity center for the aged and the reading parties that are held and grow vigorously in all areas and levels. The purpose of these activities focuses on enriching knowledge connotation and improving the spiritual realm. Strengthening people's morality is no doubt one of them. Of course, these people-based activities on the level of subject and content are relatively special. It has determined that if we want to put moral education into practice, the organizers are required to make all-round and detailed planning on aspects of activity content, activity method and activity process to seek the unification of means and purpose. Especially in boosting the moral construction of citizens in the process of basic modernization, we must improve the function and efficiency of these people-based activity platforms via the unceasing update of the content.

Broadly speaking, when boosting the moral construction of citizens at present, we have to pay attention to the platforms of people-based activities. Only by properly depending on the platform of people-based activity can we achieve the purpose of teaching through activities and assisting the spiritual modernization of people. It has proposed the requirement with more epochal character for the optimization of the content, means and ways of people-based activity. We must integrate the moral objective and content with Chinese characteristics in the people-based activities through a positive and feasible way to create it into an important platform for boosting the moral construction of citizens.

\section{To EFFICIENTLY MAKE USE OF NEW MEdiA COMMUNICATION MEANS}

New media is the product of the deep development of information technological revolution. The media means changing with each passing day such as network, mobile phone and digital television are its main contents that are high speed, convenient and interactive. China has been in a relatively leading position in the technological means of new media and its application. Therefore, in the process of taking the lead in modern modernization, we have the advantage in servicing the boosting of the moral construction of citizens. In addition, new media mainly face the young and middle-aged 
group. Therefore, seizing the opportunity brought by new media has a very profound and positive significance.

Firstly, we must use technological means and its improvement to make the boosting of the moral construction of citizens in the new era supplement the deficiencies of offline means in transmission by virtue of the network. The first thing we have to do is to reselect the existing online resources of moral education and strive to upload more kinds of materials for the moral education of citizens. In particular, we have to correspondingly and strictly control the quality of contents that embody the achievements of moral development of Chinese society since the reform and opening up in order to ensure the content of moral education online is advanced. At the same time, we have to correspondingly optimize the presentation form to make it have more sense of the times and meet the requirement of the age. Of course, fully making the network serve the moral construction of citizens does not mean we only need to ensure the content of moral education online is positive. The deeper pursuit of us is to integrate the ideas of the "Internet Plus" and big data in boosting the moral construction of citizens and create deep connection that has inner correspondence between the two. The purpose of the pursuit is to truly turn the network into the second front for the moral construction of citizens.

Secondly, we must pay high attention to the role of mobile terminals such as mobile phone. The application of such tools for social contact as WeChat on the mobile terminals has turned mobile terminals such as mobile phone into the platform of self-education. In order to more fully make the use of mobile APP to boost the moral construction of citizens, except for making "decrease" effort in purifying the network environment, we have to make "increase" effort in optimizing the push content. At present, the inarguable fact is that the daily use of mobile terminals such as mobile phone has occupied tremendous time of people. The powerful function of social contact has even changed the life style of people. Therefore, it is necessary for the boosting of the moral construction of citizens in the new era to make the moral education of citizen better adapt to the requirement of the modernization of people via the powerful function of social contact of the mobile terminals such as mobile phone. We should strive to "package" the excellent moral resources in the diffusion of proper mobile terminals at the same time do not increase the spiritual burden of the audiences.

Thirdly, we must deeply excavate the potential of digital television on the moral education via necessary technological means. Different from the television in the traditional sense, the digital television bases on the information interactive technology and has expanded the function of television in interaction and service, having increasingly become the information machine in people's daily life. Particularly, the remote education and remote diagnosis and treat can serve as important ways of the moral education on citizens. Besides, the technology of digital television and its application in China has kept one step ahead in many aspects. We do not have too many technical difficulties in serving the boosting of the moral construction of citizens in the new era. We should attach more importance to the integration of content, such as uploading more MOOC resources of ethical and moral education and properly increasing the circulation of advertisement of social morality with the nature of public benefit, in order to enhance the function of digital television in the daily moral education through the continuous optimization of content. Of course, it must be pointed out that in exerting the related functions, we should avoid the wrong region of the traditional television development and cannot simply turn it into a mechanical expounding machine or advertising machine.

To sum up, applying new media means has assisted the boosting of the moral construction of citizens and been necessary in the process of basic modernization. Under the premise that relevant technical conditions have met, we must make effort to optimize the content and form and improve the new media means when expanding its function of moral education. What is more, it is undoubted that with the further development of science and technology, brand-new new media means will spring up ceaselessly. How to make it serve the moral construction of citizens needs our continuous exploration in practice.

\section{TO INTENSIFY THE SYSTEMATIC RELEVANCY OF SPECIFIC STRATEGIES}

In the process of basic modernization, there is no doubt that the strategy of boosting the moral construction of citizens is diversified on the content level. The subject, platform and means mentioned above have laid the foundation. But no matter what kind of specific strategy, its value will never be confined to the conception. Instead, it must be implemented in reality. Its corresponding effectiveness must be reflected in the implementation. Furthermore, the internal relevancy that should exist in the strategy system can be ensured and embodied in the specific implementation of the moral construction of citizens. All of these require us to energetically improve the mechanism of giving play to the role of moral construction of citizens.

Firstly, we should optimize the corresponding mechanism of cultivating the subject consciousness. The understanding of the importance in boosting the moral construction of citizens or the planning of related strategy system and the implementation of the moral construction of citizens must establish on the basis of the subject consciousness. The subject consciousness must be cultivated. For participants in the moral construction of citizens, the development of subject consciousness must be cultivated. Boosting the moral construction of citizens in the process of basic modernization has a higher demand for cultivating the subject consciousness. Therefore, we must base on the new development in the new era and stick to the pursuit of the subject for development and progress, especially the simple wish in moral aspect. Meanwhile, we should improve the means and ways of forming subject consciousness and build and enhance the system of evaluating, correcting and improving the moral quality. We must seek breakthrough in solid and cohesion and create the mechanism of cultivating the subject's moral consciousness with a distinctive feature of the new era, in order to meet the demand of the relevancy of the strategy system on the subject condition. 
Secondly, we should optimize the system mechanism for the moral construction of citizens. The historical experience has shown system guarantee has its unique significance on the development of Chinese society. Therefore, ensuring the rules and systems to follow in boosting the moral construction of citizens in the new era is internally necessary for the development of Chinese society, except for being the distinct demand of the time. Optimizing the system mechanism for the moral construction of citizens must base on the process of basic modernization and constantly make up for the deficiencies in the related system level to form the system that guarantees ceaselessly before, in and after the event. In particular, efficient system must be established to guarantee the internal relevancy of specific strategies. Therefore, in the process of basic modernization, it is distinctly important and urgent to base on the purpose of the moral construction of citizens, optimize relevant system in the courage of overcoming difficulties and highlight the system characteristic of strategies in boosting the moral construction of citizens. Only in this way can we meet the demand of the strategy system relevancy on the system condition.

Thirdly, we should optimize the auxiliary mechanism of related rigid force. As everyone knows, the morality and its functions are in a gentle and mild way. But compared with morality and its effectiveness, as important social norm, laws and regulations and its force have an extremely strong and rigid force. "Law is the morality of bottom line and the guarantee of morality" [3] has determined we cannot neglect the rigid force of laws and regulations and its function in the moral construction. Therefore, in boosting the moral construction of citizens in the new era, we should take laws and regulations as a necessary supplement and guarantee. Especially under the background of realizing basic modernization, how to optimize the mechanism of action of rigid forces like laws and regulations is the problem that must be explored and solved in the development. On the basis of scientifically teasing laws and regulations related to the moral construction of citizens, we should aim at the demand of the era development and optimize laws and regulations on the moral construction of citizens. Meanwhile, we must guarantee the specific strategies are implemented in order and the strength of force, in order to meet the demand of the strategy system relevancy on the auxiliary condition.

In short, in the process of realizing basic modernization, to implement the boosting of the moral construction of citizens, we must energetically improve the mechanism for the function exertion of the moral construction of citizens and put effort in the internal relevancy of strategy system. At the same time, we should realize the optimization that meet the demand of the new era in the subject condition, system condition and auxiliary condition of the strategy system relevancy to ensure the subject is consciousness, the system can guarantee and the auxiliary is powerful and efficiently boost the moral construction of citizens on the whole.

\section{CONCLUSION}

In conclusion, strategies of boosting the moral construction of citizens in the process of basic modernization must closely stick to the theme of basic modernization and center on the target of boosting the moral construction of citizens. The macro guidance and micro operation, selection of moral resources, the function exertion of modern means, the edification of local culture and the promotion of specific platforms (or fields) should strongly aim at the reality and we must correspondingly ensure its efficiency. It requires benign interaction must form between related strategies and we must establish the strategy system of boosting the moral construction of citizens. Correspondingly, the efficient systematic mechanism of element is necessary, while the higher-level target is to endow the strategy system with a solid and stagger characteristic.

\section{REFERENCES}

[1] Commentary Department of People's Daily. Xi Jinping's Allusion [M], Beijing: People's Daily Press, 2015: preface 1

[2] Luo Guojie. Ethics (Revised Edition) [M], Beijing: People's Publishing House, 2014: 457

[3] Xi Jinping. Xi Jinping's Opinion on Ruling State and Dealing with Politics (the $2^{\text {nd }}$ Volume) [M], Beijing: Foreign Language Press, 2017: 134 